\title{
Rancang Bangun Aplikasi Mobile Rekomendasi Layanan Kesehatan Berdasarkan Lokasi Pengguna Memanfaatkan Google Place
}

\author{
Stefanus Candra Kusuma Wardana, Dwi Sunaryono, dan Sarwosri \\ Jurusan Teknik Informatika, Fakultas Teknologi Informasi, Institut Teknologi Sepuluh Nopember (ITS) \\ Jl. Arief Rahman Hakim, Surabaya 60111 Indonesia \\ e-mail: dwi@if.its.ac.id; sri@its-sby.edu
}

\begin{abstract}
Abstrak-Banyaknya layanan kesehatan yang tersebar di berbagai pelosok daerah membuat masyarakat dimudahkan untuk mendapatkan jaminan kesehatan yang layak. Akan tetapi banyak masyarakat yang terpaku kepada nama besar suatu instansi kesehatan. Karena terlalu ramai dan padat suatu instansi kesehatan yang mempunyai nama besar, maka banya masyarakat yang terlambat mendapatkan layanan kesehatan. Untuk membantu masyarakat mendapatkan dan menemukan layanan kesehatan yang sesuai dengan kebutuhan pasien, dibuatlah aplikasi yang memberikan rekomendasi layanan kesehatan yang didalamnya juga terdapat pencarian layanan kesehatan berdasarkan lokasi. Metode yang digunakan untuk memberikan rekomendasi adalah metode Cosine Similarity. Aplikasi ini dibangun dengan menggunakan platfrom Android sehingga pengguna dimudahkan dalam penggunaannya. Cosine Similarity digunakan untuk memberikan rekomendasi berdasarkan kemiripan dokumen kata kunci pencarian dengan database server. Semakin banyak tingkat kemiripan maka nilai rekomendasi semakin tinggi. Pada rekomendasi ditambahkan fitur Google Maps dan Google Place untuk memberikan peta digital serta untuk menentukan layanan yang ada disekitar pengguna.
\end{abstract}

Kata Kunci-Cosine Similarity, Google Maps, Google Place

\section{PENDAHULUAN}

$\mathrm{K}$ ESEHATAN merupakan salah satu kebutuhan primer manusia yang digunakan untuk menunjang kebutuhan fisiologis setiap manusia. Kebutuhan dasar manusia menurut Abraham Maslow dalam teori Hirarki terdiri dari kebutuhan fisiologis, kemanan, cinta, harga diri, dan aktualisasi diri [1]. Pelayanan kesehatan adalah pengunaan fasilitas pelayanan yang disediakan baik dalam bentuk rawat jalan, rawat inap, kunjungan rumah oleh petugas kesehatan ataupun bentuk kegiatan lain [2].

Dengan memanfaatkan Google Places dan Google Maps dapat ditentukan lokasi pelayanan kesehatan yang dibutuhkan oleh pasien. Rekomendasi layanan kesehatan yang dibutuhkan disesuaikan dengan penyakit yang diderita pasien serta persyaratan yang dibutuhkan untuk mendapatkan pelayanan kesehatan yang dituju. Kata kunci pencarian berupa jenis penyakit, fasilitas serta lokasi merupakan parameter yang digunakan untuk membuat daftar rekomendasi pelayanan kesehatan yang dibutuhkan. Untuk melakukan pencarian daftar rekomendasi maka digunakan metode Cosine Similarity. Penggunaan metode Cosine Similarity didasarkan pada kedekatan yang di dapatkan dari kedua vektor (dokumen) dapat dengan mudah untuk dihitung. Metode ini juga memungkinkan perubahan bobot dari term yang digunakan dengan sederhana dan mudah.

\section{TINJAUAN PUSTAKA}

\section{A. Layanan Kesehatan}

Layanan Kesehatan adalah setiap upaya yang diselenggarakan sendiri atau secara bersama - sama dalam suatu organisasi untuk memelihara dan meningkatkan kesehatan, mencegah dan menyembuhkan penyakit serta memulihkan kesehatan perorangan, keluarga, kelompok dan ataupun masyarakat.

Layanan kesehatan terdiri dari layanan kesehatan tingkat primer, sekunder dan tersier. Layanan kesehatan yang dibahsa dalam aplikasi rekomendasi ini meliputi layanan kesehatan rumah sakit dan layanan kesehatan puskesmas.

\section{B. Term Frequency dan Invers Document Frequency}

Term Frequency adalah cara untuk mengukur seberapa sering sebuah term/istilah muncul dalam sebuah dokumen. Karena setiap dokumen mempunyai panjang yang berbeda maka kemungkinan untuk suatu term muncul pada dokumen yang panajang akan lebih besar.

Invers Document Frequency adalah metode untuk menghitung tingkat kepentingan suatu term. Setelah term frequency dihitung maka dihitung bobot dari term tersebut [3].

$\operatorname{idf}(t, D)=\log \left(1+\frac{N}{|\{d \in D: t \in d\}|}\right)$

$\mathrm{N}=$ Jumlah dokumen

$|\{d \in D: t \in d\}|=$ Jumlah dokumen yang terdapat term didalamnya.

\section{Cosine Similarity}

Cosine similarity adalah metode yang digunakan untuk menghitung kemiripan antara dua parameter vektor dari sudut kosinus yang terbuat diantara kedua parameter tersebut. Vektor tersebut didasarkan pada jumlah kata yang mirip pada kedua dokumen teks. Jika nilai kosinus-nya adalah 1, maka parameter vektor tersebut benar-benar identik. Dan jika nilainya 0 , maka kedua parameter vektor tersebut sama sekali tidak mempunyai 
kemiripan [4].

Langkah-langkah yang dilakukan untuk menggunakan metode Cosine Similarity pertama adalah menentukan bobot setiap term dalam dokumen yang akan dihitung. Kedua hitung kemiripan vektor (dokumen) pada query dengan setiap dokumen yang ada. Ketiga hitung semua hasil query dengan rumus lalu urutkan berdasarkan nilainya. Rumus yang digunakan untuk menghitung Cosine Similarity adalah:

$$
\cos (x, y)=\frac{x \cdot y}{\|x\|\|y\|}
$$

Dimana,

$x \cdot y=$ vektor dot product dari $\mathrm{x}$ dan $\mathrm{y}$

$\|x\|=$ panjang dari vektor $\mathrm{x}$

$\|y\| \quad=$ panjang dari vektor $\mathrm{y}$

\section{Google Maps dan Google Place}

Google Maps adalah layanan peta digital paling populer dan terefektif yang ada di internet saat ini. Google Maps menyediakan gambar pemetaan dari seluruh permukaan bumi. Layanan ini juga dapat menyediakan penunjuk arah ke setiap lokasi tujuan dan bahkan menghitung jarak terpendek dan rute perjalanan termurah.

Google Places adalah salah satu layanan Google yang menggunakan basis data yang sama dengan Google Maps dan Google+ Local. Google Places API memungkinkan aplikasi berbasis lokasi mendapatkan informasi detail mengenai tempat dari berbagai kategori. Google Places API dilengkapi dengan lebih dari 95 juta lokasi bisnis dan lokasi menarik yang diperbarui secara berkala. Pembaruan dapat dilakukan melalui pemilik bisnis yang terdaftar maupun kontribusi dari pengguna [5].

\section{ANALISIS DAN PERANCANGAN}

\section{A. Analisi Permasalahan}

Permasalahan utama yang diangkat dalam pembuatan Tugas Akhir ini adalah bagaimana memberikan rekomendasi pencarian layanan kesehatan sesuai preferensi pengguna. Permasalahan kedua adalah bagaimana memberikan rekomendasi layanan kesehatan yang ada disekitar lokasi pengguna. Permasalahan ketiga adalah bagaimana menyediakan data informasi dari beberapa layanan kesehatan yang sesuai dengan pencarian pengguna.

Rekomendasi layanan kesehatan didapat dengan mengumpulkan informasi data dari Dinas Kesehatan Kota Surabaya, pencocokan koordinat dengan alamat menggunakan Google Maps dan Google Earth serta meninjau lokasi langsung untuk data tempat yang akurat. Beberapa infomasi layanan kesehatan yang diambil antara lain mencakup alamat, nomor telepon, fasilitas kesehatan, dan jenis dokter yang bertugas di layanan kesehatan tersebut.

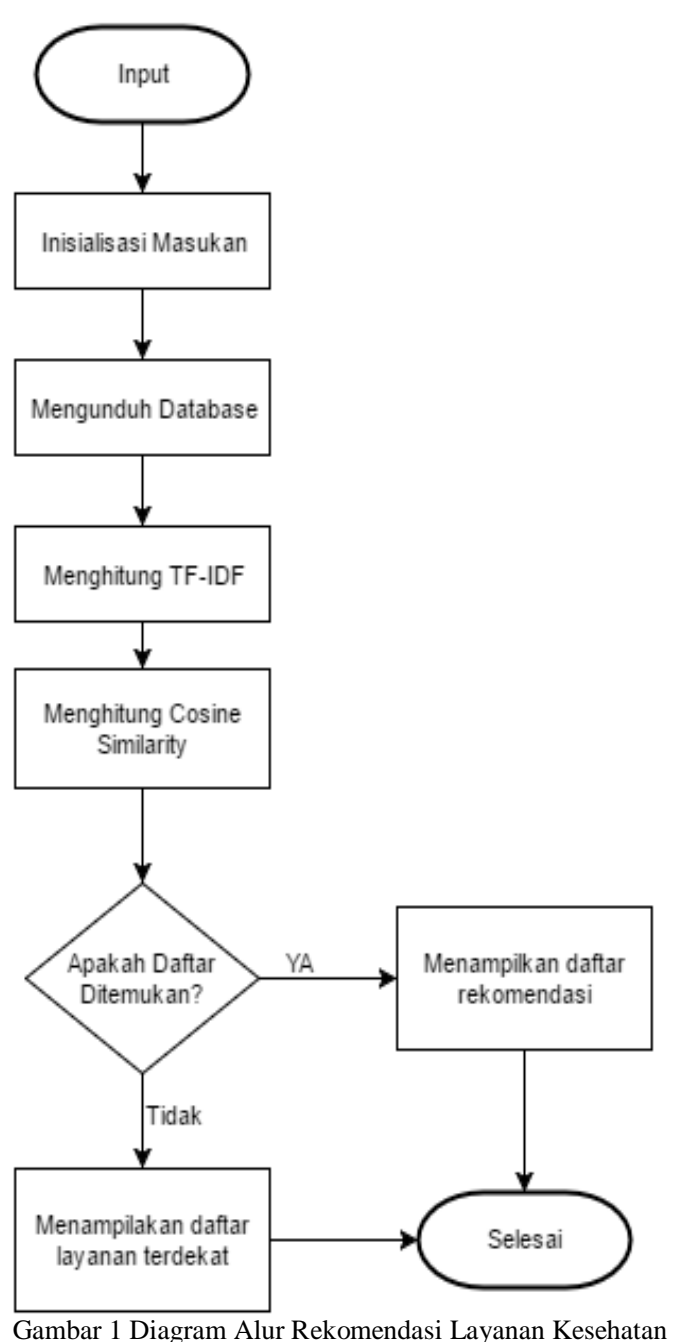

\section{B. Kebutuhan Fungsional}

Kebutuhan fungsional berisi proses-proses yang harus dimiliki sistem. Kebutuhan fungsional mendefinisikan layanan yang harus disediakan dan reaksi sistem terhadap masukan atau pada situasi tertentu. Daftar kebutuhan fungsional dapat dilihat pada Tabel 1.

Tabel 1

Tabel Kebutuhan Fungsional Aplikasi

\begin{tabular}{|c|c|c|}
\hline $\begin{array}{c}\text { Kode } \\
\text { Kebutuhan }\end{array}$ & Kebutuhan Fungsional & Deskripsi \\
\hline F-0001 & $\begin{array}{l}\text { Menangkap Koordinat } \\
\text { Posisi Pengguna }\end{array}$ & $\begin{array}{l}\text { Sistem menangkap koordinat } \\
\text { posisi pengguna saat ini dan } \\
\text { mendapatkan nilai latitude dan } \\
\text { longitude. }\end{array}$ \\
\hline F-0002 & $\begin{array}{l}\text { Melihat Daftar Layanan } \\
\text { Kesehatan Terdekat }\end{array}$ & $\begin{array}{l}\text { Pengguna dapat melihat daftar } \\
\text { Layanan Kesehatan terdekat } \\
\text { dari posisi pengguna saat ini } \\
\text { menggunakan Google Place. }\end{array}$ \\
\hline F-0003 & $\begin{array}{l}\text { Melihat Detil Layanan } \\
\text { Kesehatan Terdekat }\end{array}$ & $\begin{array}{l}\text { Pengguna dapat melihat detail } \\
\text { informasi dari masing-masing } \\
\text { Layanan Kesehatan dengan } \\
\text { atribut nama, alamat, nomor } \\
\text { telepon, dan informasi fasilitas } \\
\text { layanan kesehatan }\end{array}$ \\
\hline F-0004 & $\begin{array}{l}\text { Melihat Lokasi Layanan } \\
\text { Kesehatan Terdekat Pada } \\
\text { Peta }\end{array}$ & $\begin{array}{l}\text { Pengguna dapat melihat lokasi } \\
\text { Layanan Kesehatan pada peta } \\
\text { digital (Google Maps) relatif } \\
\text { terhadap posisi pengguna saat } \\
\text { ini. }\end{array}$ \\
\hline
\end{tabular}




\begin{tabular}{|c|c|c|}
\hline F-0005 & $\begin{array}{l}\text { Melakukan Panggilan ke } \\
\text { Layanan Kesehatan }\end{array}$ & $\begin{array}{l}\text { Pengguna dapat melakukan } \\
\text { panggilan kepada layanan } \\
\text { kesahatan yang dituju. }\end{array}$ \\
\hline F-0006 & $\begin{array}{l}\text { Melihat Panduan } \\
\text { Perjalanan dari Lokasi } \\
\text { Pengguna ke Layanan } \\
\text { Kesehatan }\end{array}$ & $\begin{array}{l}\text { Pengguna dapat melihat } \\
\text { panduan perjalanan } \\
\text { menggunakan Google Drive } \\
\text { dari posisi pengguna ke tempat } \\
\text { layanan kesehatan yang dipilih. }\end{array}$ \\
\hline F-0007 & $\begin{array}{l}\text { Melihat Daftar } \\
\text { Rekomendasi Layanan } \\
\text { Kesehatan }\end{array}$ & $\begin{array}{l}\text { Pengguna dapat melihat } \\
\text { rekomendasi } \\
\text { Kesehatan berdasarkan kata } \\
\text { kunci yang dimasukkan }\end{array}$ \\
\hline F-0008 & $\begin{array}{l}\text { Memperbaharui data } \\
\text { Layanan Kesehatan pada } \\
\text { basis data layanan }\end{array}$ & $\begin{array}{l}\text { Administrator Memperbaharui } \\
\text { data layanan kesehatan pada } \\
\text { server basis data }\end{array}$ \\
\hline
\end{tabular}

\section{IMPLEMENTASI}

\section{A. Implementasi Proses Rekomendasi Layanan Kesehatan}

Pada implementasi rekomendasi layanan terdekat dengan metode Cosine Similarity pada awal dihitung bobot dari TFIDFnya. Proses perhitungan TF-IDF dapat dilihat pada kode 1 berikut.

tfCalculator adalah fungsi yang digunakan untuk menghitung bobot dari setiap term pada dokumen. Sedangkan idfCalculator digunakan untuk menghitung hasil invers dari bobot dokumen yang didapatkan dari perhitungan TF-IDF.

Setelah proses perhitungan TF-IDF maka dihitung bobot Cosine Similarity dengan rumus 1, di implementasikan pada kode 2.

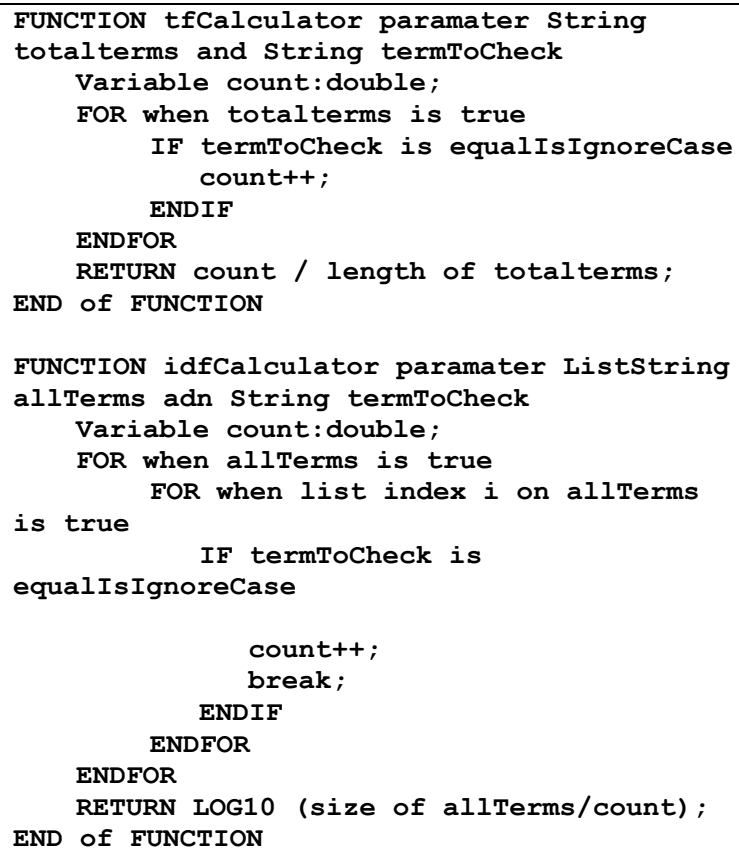

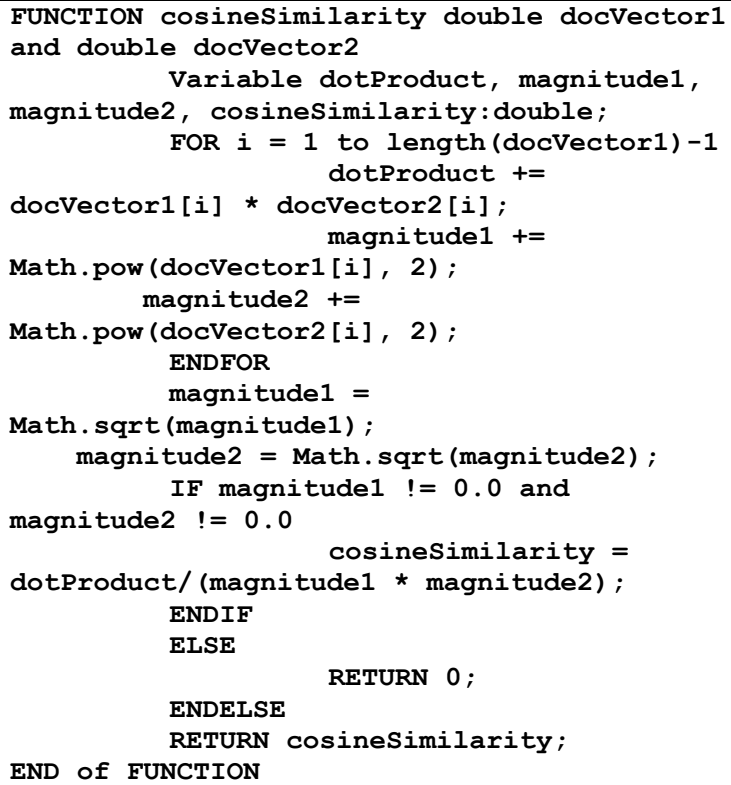

Kode Sumber 2 Implementasi Cosine Similarity

\section{B. Implementasi Antarmuka}

Pada implementasi antarmuka dibuat antarmuka sesuai dengan rancangan antarmuka supaya pengguna dapat mudah untuk menggunakan aplikasi.

Antarmuka pencarian pada Gambar 2 berisi textbox untuk menampung kata kunci dari pengguna. Antarmuka hasil pencarian pada Gambar 3 berisi daftar hasil pencarian, baik rekomendasi layanan kesehatan maupun hasil pencarian layanan kesehatan terdekat.

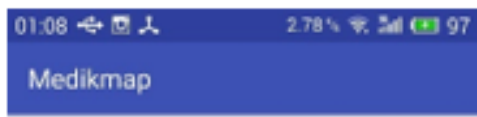

Masukan Pencarian

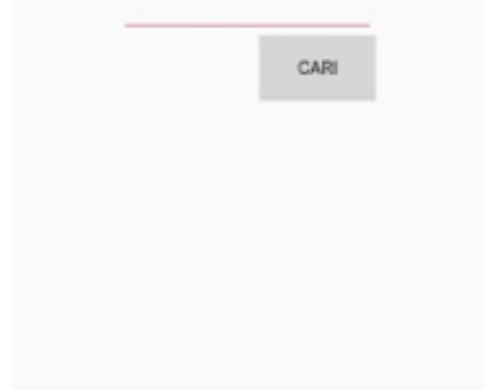




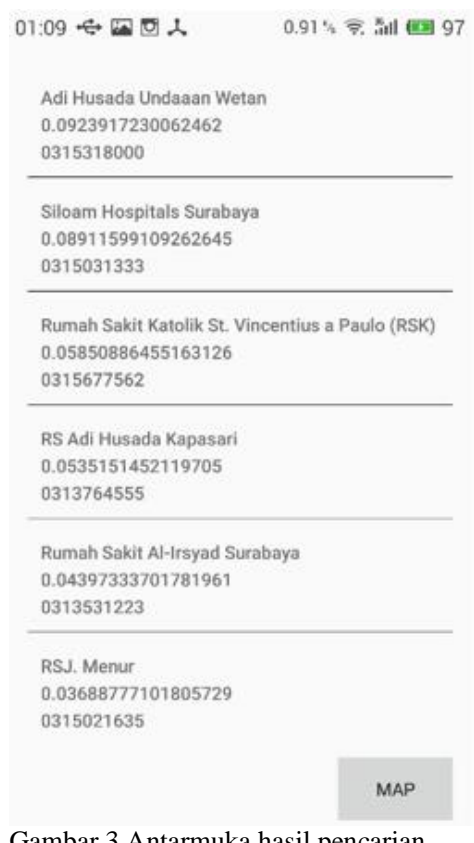

\section{KESIMPULAN}

Kesimpulan yang dapat diambil dalam Tugas Akhir ini adalah sebagai berikut:

1. Dengan layanan Google Place, aplikasi dapat melakukan pencarian lokasi Layanan Kesehatan dengan kata kunci dan lokasi antara pengguna dengan Layanan Kesehatan yang dicari. Aplikasi ini juga dapat menampilkan informasi masing-masing layanan kesehatan antara lain alamat dan nomor telepon.

2. Dengan layanan Google Maps maka aplikasi ini dimungkinkan dapat memberitahukan kepada pengguna lokasi gambaran hasil pencarian pada peta digital. Dengan Google Maps aplikasi ini juga dapat memperhitungkan jarak ke lokasi dan estimasi waktu perjalanan.

3. Aplikasi ini berhasil memberikan rekomendasi layanan kesehatan dengan metode Cosine Similarity.

4. Aplikasi ini dapat menampilkan detil layanan kesehatan, sehingga pengguna dapat melihat fasilitas apa saja yang terdapat pada Layanan Kesehatan tersebut. Serta fitur Call untuk menghubungi pihak Layanan Kesehatan yang dituju.

\section{DAFTAR PUSTAKA}

[1] A. Patricia, Fundamental Keperawatan, Jakarta: EGC, 2005.

[2] Azwar, Administrasi kesehatan, Jakarta: PT. Bina Putra, 2006.

[3] H. C. Wu, R. W. Luk, K. F. Wong dan K. L. Kwok, "ACM Transactions on Information Systems (TOIS)," Interpreting TF-IDF term weights as making relevance decisions, vol. 26, no. 3, 2008.

[4] I. Sudanawati, Metode Bayesian Network dan Cosine Similarity untuk Sistem Identifikasi Kontrol Keamanan Informasi, Surabaya: Jurusan Teknik Informatika ITS, 2011.

[5] D. Arganto, Aplikasi Mobile Rekomendasi Pencarian Obat dan Apotek Memanfaatkan Google Maps, Surabaya: Teknik Informatika ITS, 2014. 